\title{
Ross operation after failure of aortic valve repair
}

\author{
Karen B. Abeln ${ }^{1 \#}$, Vincent Chauvette ${ }^{2 \#}$, Nancy Poirier ${ }^{2}$, Shunsuke Matsushima ${ }^{3}$, Ismail El-Hamamsy ${ }^{4}$, \\ Hans-Joachim Schäfers ${ }^{1}$
}

${ }^{1}$ Department of Thoracic and Cardiovascular Surgery, Saarland University Medical Center, Homburg (Saar), Germany; ${ }^{2}$ Division of Cardiac Surgery, Montreal Heart Institute, Université de Montreal, Montreal, Canada; ${ }^{3}$ Department of Cardiovascular Surgery, Kobe Children's Hospital, Kobe, Japan; ${ }^{4}$ Department of Cardiothoracic Surgery, The Mount Sinai Medical Center, New York, NY, USA

\#These authors contributed equally to this work.

Correspondence to: Hans-Joachim Schäfers, MD, PhD. Department of Thoracic and Cardiovascular Surgery, Saarland University Medical Center, Homburg (Saar), Germany. Email: h-j.schaefers@uks.eu.

Background: Repair failure remains one of the most important complications of aortic valve reconstruction. Young patients might benefit from a Ross procedure in such a scenario, provided it can be performed safely and with adequate durability. The aim of this study was to assess the safety and clinical outcomes of a Ross operation following a failed repair.

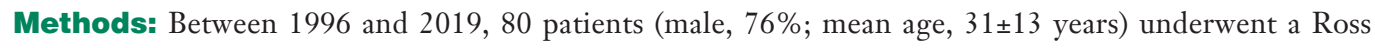
procedure after a median of $6.6(1.7-15.9)$ years following an initial aortic valve repair. The previous valve repair was performed for unicuspid (53\%), bicuspid (39\%), tricuspid (7\%), and quadricuspid morphology (1\%). Median follow-up after the Ross operation was $2.8(0.964-13.25)$ years, mean $5 \pm 5$ years $(92 \%$ complete).

Results: Median cardiopulmonary bypass and cross-clamp times were 144 [106-154] minutes and 98 [79113] minutes, respectively. Thirty-two patients (40\%) required a concomitant procedure, most commonly, an ascending aortic replacement $(n=23)$. There were no peri-operative deaths, myocardial infarctions, or neurological complications. There was one late death from a non-cardiac cause. At 10 years, overall survival was $99 \% \pm 1 \%$, similar to that of an age- and gender-matched population. Nine patients required re-intervention after their Ross procedure (five on the autograft and four on the pulmonary conduit). The autograft re-interventions were valve-sparing procedures in all patients. The cumulative incidence of reintervention on the autograft at 8 years was $5.1 \% \pm 3.1 \%$.

Conclusions: The stepwise strategy of an initial valve repair followed by Ross operation represents a safe and valid option for failed aortic valve repair. It is associated with low peri-operative morbidity. Mid-term survival is excellent, similar to that of a matched general population. The probability of re-intervention after the Ross procedure appears similar to that of a primary Ross operation, deeming it a warranted consideration in cases of failed aortic valve repair.

Keywords: Ross procedure; aortic valve repair; aortic regurgitation (AR); aortic valve repair failure; aortic valve replacement (AVR)

Submitted Sep 10, 2020. Accepted for publication Jan 22, 2021.

doi: 10.21037/acs-2020-rp-19

View this article at: http://dx.doi.org/10.21037/acs-2020-rp-19

\section{Introduction}

The ideal treatment of aortic valve disease in young adults remains a matter of debate. Young and middle-aged patients have longer life expectancy, which exposes them to a prolonged period of cardiac- and prosthesis-related complications. In addition, they have a higher level of physical activity than their elderly counterparts. In recent years, aortic valve repair has evolved into an alternative 
to replacement. It offers several potential advantages over mechanical aortic valve replacement (AVR): lack of anticoagulation, low risk of infection, and excellent hemodynamics (1). While more long-term results of valve repair are yet to be obtained, it may not be a lifelong solution for many young individuals, in particular those with bicuspid or unicuspid morphology $(2,3)$. In fact, repair failure with the need for re-operation has been found to be the most frequent valve-related complication (4). In these instances, aortic valve repair could be considered a bridge to AVR in order to minimize the probability of valve-related complications.

Mechanical AVR has long been the standard operation after a failed valve repair in young patients. Given the limitations of available prostheses (5), the Ross procedure has gained increasing attention in past years (6). It results in almost physiological aortic valve hemodynamics and low incidence of complications. More importantly, the procedure achieves long-term survival equivalent to that of the ageand gender-matched general population (7). However, the increased complexity of a Ross procedure in the context of redo surgery may be associated with increased perioperative morbidity. Moreover, concerns remain regarding dilatation of the pulmonary autograft, especially in patients with pre-operative aortic regurgitation (AR) and dilated annulus (8). This is all the more important given that almost all failed repairs will have had regurgitation as the initial pathology (2). At this time, there is limited data on the safety and durability of the Ross procedure for the purpose of re-operation, particularly after a failed aortic valve repair in adults.

This study addresses mid-term results using the Ross procedure as a surgical option for failed aortic valve repair. Primary endpoints were survival and cumulative incidence of autograft re-intervention; secondary endpoints were freedom from AR, aortic root dilatation, peri-operative morbidity, and freedom from valve-related complications.

\section{Methods}

\section{Patient population}

Between April 1996 and December 2019, 80 consecutive patients (mean age: $31 \pm 13$ years, $76 \%$ male) underwent a Ross procedure after failed aortic valve repair at the Saarland University Medical Center, Germany ( $\mathrm{n}=52$ patients), and Montreal Heart Institute, Canada ( $\mathrm{n}=28$ patients). Patients were included in the study if they underwent at least one aortic valve repair prior to the Ross procedure. Three patients had a mechanical valve implanted for failed repair prior to the Ross procedure. Baseline characteristics of the cohort are found in Table 1.

The investigation was approved by the respective ethics committees (Saarland Regional Ethics Committee, CEP 203/19; Montreal Heart Institute Ethics Committee, \#F11c-10897), and individual patient consent was waived for the analysis and publication in anonymized fashion.

These patients underwent the Ross procedure a median of $6.6(1.7-15.9)$ years following their last aortic valve repair. The indication for surgery was aortic stenosis in 13 patients $(16 \%)$, AR in $21(26 \%)$, combined disease in $40(50 \%)$, and active infective endocarditis in $6(8 \%)$ patients. Original aortic valve morphology was unicuspid in 42 patients (53\%), bicuspid in $31(39 \%)$, tricuspid in $6(7 \%)$, and quadricuspid in 1 patient (1\%). Six patients $(8 \%)$ had a left ventricular ejection fraction (LVEF) $<50 \%$. All patients were prospectively followed both clinically and echocardiographically. Median and mean follow-up were $2.8(1.0-13.3)$ years and $5 \pm 5$ years, respectively. Follow-up was $92 \%$ complete (385 patient-years).

\section{Surgical technique}

Three experienced surgeons (NP, IEH, and HJS) performed the Ross procedures. The freestanding full-root technique was used in all instances; technical details have been described elsewhere $(9,10)$. The autograft was implanted in subannular (Montreal cohort) or intra-annular (Homburg cohort) position. The proximal autograft anastomosis was performed by interrupted (Montreal) or continuous (Homburg) sutures.

If the tubular diameter of the ascending aorta exceeded $>38-40 \mathrm{~mm}$ (Montreal cohort) or $>30-35 \mathrm{~mm}$ (Homburg cohort), the tubular ascending aorta was replaced with a 26- or 28-mm Dacron graft to ensure sinotubular junction (STJ) stabilization (11). In patients with a dilated annulus (>26 mm, n=23), an external annuloplasty was added, using a circular Dacron ring (Montreal cohort; $n=11$ ), an expanded polytetrafluoroethylene (ePTFE) suture (GoreTex CV-0; W.L. Gore \& Assoc., Munich, Germany) for the Homburg cohort between 2010 and $2019(\mathrm{n}=7)$, or pericardial strip (Homburg cohort; 1997-2011; n=2). For external root stabilization, the remnants of the native aortic root (i.e., in the area of aortic commissures) were fixed to the sinotubular suture, placed outside the autograft root $(\mathrm{n}=42)(10)$. 


\begin{tabular}{|c|c|}
\hline Patient characteristics & $\mathrm{N}=80$ \\
\hline Male sex, $\mathrm{n}[\%]$ & $61[76]$ \\
\hline Age, median [IQR] & 32 [28-43] \\
\hline \multicolumn{2}{|l|}{ Site, $\mathrm{n}[\%]$} \\
\hline Homburg & $51[64]$ \\
\hline Montreal & 29 [36] \\
\hline Time after aortic valve repair, median [IQR], y & $6.6[1.7-15.9]$ \\
\hline \multicolumn{2}{|l|}{ Cardiovascular risk factors, $\mathrm{n}[\%]$} \\
\hline BMI, mean \pm SD & $26.4 \pm 5.4$ \\
\hline Diabetes & $1[1]$ \\
\hline Dyslipidemia & 7 [9] \\
\hline Art. hypertension & 26 [33] \\
\hline Coronary artery disease & $1[1]$ \\
\hline Chronic kidney disease & $1[1]$ \\
\hline Smoker & $12[15]$ \\
\hline I.V. drug abuse & $1[1]$ \\
\hline \multicolumn{2}{|l|}{ Surgical indication, n [\%] } \\
\hline Isolated aortic stenosis & $13[16]$ \\
\hline Isolated AR & 26 [33] \\
\hline Mixed lesion & $41[51]$ \\
\hline Endocarditis & $6[8]$ \\
\hline \multicolumn{2}{|l|}{ Valve morphology, n [\%] } \\
\hline Unicuspid & $42[53]$ \\
\hline Bicuspid & 31 [39] \\
\hline Tricuspid & $6[7]$ \\
\hline Quadricuspid & $1[1]$ \\
\hline Prosthesis (mechanical) & $4[5]$ \\
\hline \multicolumn{2}{|l|}{ AR grade, $n[\%]$} \\
\hline I & 10 [13] \\
\hline II & $20[25]$ \\
\hline III or IV & $44[55]$ \\
\hline \multicolumn{2}{|l|}{ Aortic root diameter, median [IQR], mm } \\
\hline Annulus & 24 [22-27] \\
\hline Sinus & $31[29-35]$ \\
\hline STJ & 27 [24-31] \\
\hline
\end{tabular}

Table 1 (continued)
Table 1 (continued)

\begin{tabular}{ll}
\hline Patient characteristics & $\mathrm{N}=80$ \\
\hline Aortic basal annulus $>26 \mathrm{~mm}, \mathrm{n}[\%]$ & $23[29]$ \\
\hline EuroSCORE II, median [IQR] & $1.3[1-3]$ \\
\hline LVEF, mean $\pm \mathrm{SD}, \%$ & $63 \pm 11$ \\
\hline LVEF $<50 \%, \mathrm{n}[\%]$ & $6[8]$ \\
\hline LVEDd, mean $\pm \mathrm{SD}, \mathrm{mm}$ & $55 \pm 11$ \\
\hline Aortic valve gradient, mean $\pm \mathrm{SD}, \mathrm{mmHg}$ & $35 \pm 19$ \\
\hline Aortic valve gradient, max $\pm \mathrm{SD}, \mathrm{mmHg}$ & $61 \pm 32$ \\
\hline $\begin{array}{l}\text { IQR, interquartile range; SD, standard deviation; AR, aortic } \\
\text { regurgitation; STJ, sinotubular junction; LVEF, left ventricular } \\
\text { ejection fraction; LVEDd, left ventricular end-diastolic diameter. }\end{array}$
\end{tabular}

\section{Follow-up}

This is a retrospective analysis of prospectively collected data. All patients were seen regularly by referring cardiologists or the institutional clinic. Echocardiograms or their reports from both institutions and patients' cardiologists, were reviewed. In addition, the patients were contacted via phone or seen in clinic to determine current functional status. The cause of death was determined by review of hospital charts or information was sought from respective primary care physicians.

\section{Statistical analysis}

Descriptive statistics are presented as mean $[ \pm$ standard deviation (SD)] or median [interquartile range (IQR)]. The date of first occurrence of AR grade $>2+$ was recorded for time-to-event calculations. The cumulative incidence of AR and aortic valve re-intervention were calculated using the $\mathrm{R}$ cmprsk package with mortality as a competing risk. Survival was analyzed using the Kaplan-Meier method. Expected survival of an age- and gender-matched population was obtained using the Ederer II method. The estimated age, gender and year-of-surgery-matched population survival curve was compared with the population of this study. Survival and cumulative incidence of re-intervention were calculated at 1, 5, 8 and 10 years. Changes in aortic root dimensions were depicted using a spline regression model. For dichotomization purposes, a root diameter (sinus of Valsalva) $\geq 45 \mathrm{~mm}$ was considered dilated. A P value $<0.05$ was considered significant for all analyses. All 


\begin{tabular}{ll} 
Table 2 Perioperative data & \\
\hline Parameters & $\mathrm{N}=80, \mathrm{n}[\%]$ \\
\hline Myocardial infarction & 0 \\
\hline Renal replacement therapy & 0 \\
\hline Bleeding complications & 0 \\
\hline Stroke & 0 \\
\hline Postoperative blood transfusion & $12[15]$ \\
\hline Permanent pacemaker implantation & $1[1]$ \\
\hline Ventricular complications (RVAD) & $1[1]$ \\
\hline RVAD, right ventricular assist device. & \\
\hline
\end{tabular}

\begin{tabular}{|c|c|}
\hline Parameters & $\mathrm{N}=80$ \\
\hline \multicolumn{2}{|l|}{ Annular support, n [\%] } \\
\hline Pericardial strip & 16 [20] \\
\hline PTFE suture & 16 [20] \\
\hline STJ Dacron ring & $11[14]$ \\
\hline Aortic wall inclusion & $42[53]$ \\
\hline \multicolumn{2}{|l|}{ RV-PA prosthesis, $\mathrm{n}$ [\%] } \\
\hline Contegra & 12 [15] \\
\hline Pulmonary homograft & 68 [85] \\
\hline \multicolumn{2}{|l|}{ Concomitant procedure, n [\%] } \\
\hline Ascending aorta replacement & 23 [29] \\
\hline Septal myectomy & $6[8]$ \\
\hline Hemi-arch using circulatory arrest & $3[4]$ \\
\hline Rescue CABG & $1[1]$ \\
\hline Tricuspid valve repair & $1[1]$ \\
\hline Mitral valve repair & $2[3]$ \\
\hline Perfusion time, median [IQR], min & $144[106-154$ \\
\hline Cross-clamp time, median [IQR], min & 98 [79-113] \\
\hline LOS, median [IQR] & $6[6-7]$ \\
\hline \multicolumn{2}{|c|}{$\begin{array}{l}\text { PTFE, polytetrafluoroethylene; STJ, sinotubular junction; RV-PA, } \\
\text { right ventricle to the pulmonary artery; CABG, coronary artery } \\
\text { bypass graft; IQR, interquartile range; LOS, length of stay. }\end{array}$} \\
\hline
\end{tabular}

statistical analyses were performed using $\mathrm{R}$ version 3.6.0 ( $\mathrm{R}$ Foundation for Statistical Computing, Vienna, Austria).

\section{Results}

\section{Operative data}

Thirty-two patients (40\%) had a concomitant procedure, most commonly ascending aortic replacement $(n=23)$ and septal myectomy $(n=6)$. There were no peri-operative myocardial infarctions, neurological, or bleeding complications. There were no operative or 30-day mortalities (Table 2).

One patient $(1.3 \%)$ required a permanent pacemaker implantation. Another patient required a temporary right ventricular assist device (RVAD). The patient presented with NYHA 3 and a right coronary artery (RCA) anomaly (high coronary origin) at the time of the Ross procedure. In addition to the Ross procedure, a coronary artery bypass on the RCA was performed for right ventricular dysfunction. The patient was weaned from extracorporeal circulation but exhibited borderline low output syndrome. Thus, an RVAD was implanted and weaned 5 days later. The patient had no further complications or re-interventions since and continues to do well.

Intra-operative data is presented in Table 3.

\section{Survival}

One patient died from a non-cardiac cause (hepatic failure due to Alagille syndrome) during follow-up. Survival was $100 \%$ at 1 year, and $98.4 \% \pm 1.5 \%$ at 5 and 10 years, respectively. This was equivalent to that of an age- and gender-matched general population (Figure 1).

\section{Autograft re-intervention}

Five patients required autograft re-intervention at a median of 4.3 (1.1-8.6) years after the Ross procedure. At 8 years, the cumulative incidence of re-intervention on the autograft was $5.1 \% \pm 3.1 \%$ (Figure 2 ).

There were two early re-operations for recurrent isolated $\mathrm{AR}>2$. One patient had a limited root cavity at the non-coronary base of the autograft. Endocarditis was 


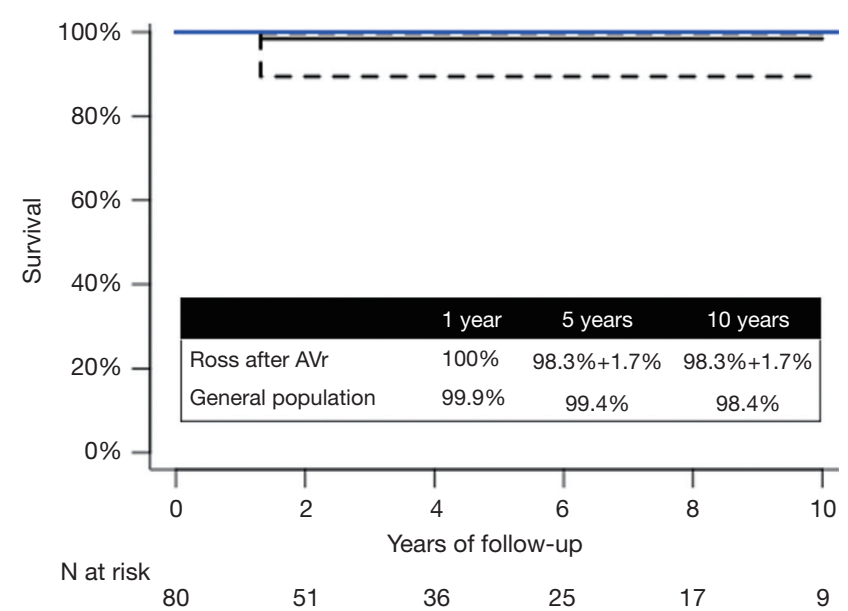

Figure 1 Survival in patients undergoing a Ross procedure after an initial aortic valve repair (black) compared with that of the ageand gender- matched population (blue). Dotted line represents $95 \%$ confidence interval.

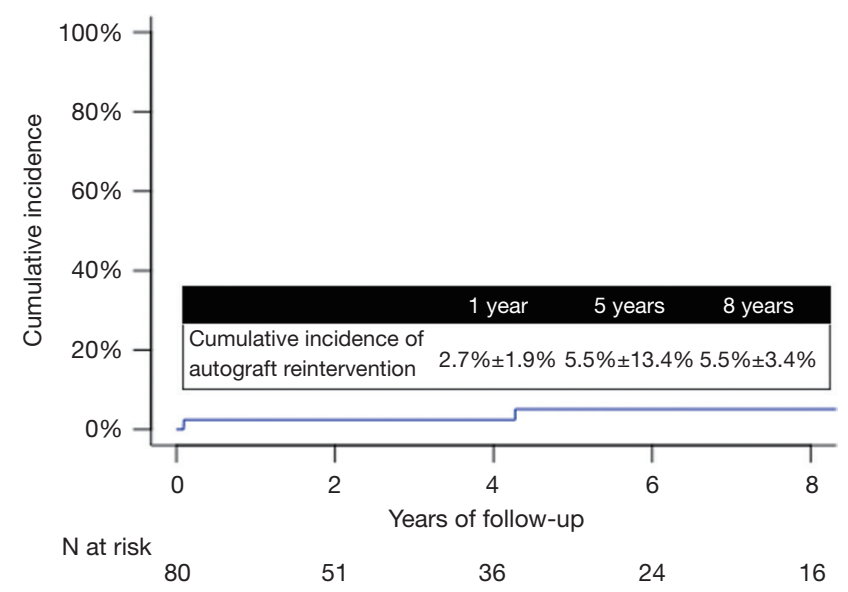

Figure 2 Cumulative incidence of reintervention on the autograft in patients undergoing a Ross procedure after an initial valve repair (blue).

suspected, but cultures and polymerase chain reaction (PCR) studies remained negative. A presumptive diagnosis of local dehiscence following infundibular muscle necrosis, was proposed. The cavity was excluded with a pericardial patch, thus also restoring autograft geometry. The second patient presented with endocarditis due to enterococcus on the autograft 33 days post-operatively; the homograft was not affected. The patient underwent aortic valve repair including patch closure of a left cusp perforation and exclusion of a septal abscess cavity, subsequently treated with antibiotic treatment. There have been no complications since.

Three patients underwent late re-interventions. Two patients presented with recurrent $A R>2$ and autograft root dilatation after 10 and 13 years, respectively. One patient had previously undergone aortic valve re-implantation for root aneurysm and AR with a tricuspid aortic valve. The other had separate unicuspid valve repair and tubular replacement of the ascending aorta. Due to lack of sufficient autologous root tissue, an external stabilization had not been performed as part of the Ross procedure. Both patients were re-operated for cusp prolapse and autograft dilatation. A valve-sparing procedure (root remodeling) was successfully performed in both cases.

The third patient presented with a large cavity below the non-coronary cusp of the autograft, 4.3 years postoperatively. Endocarditis was presumed, but all cultures and PCR studies remained negative. The most likely reason was once again deemed local myocardial necrosis of the autograft and a root suture line which had not completely eliminated the myocardial base. The patient underwent exclusion of the cavity with a pericardial patch. There have been no complications since, with last follow-up 7 years after re-intervention.

No patient with initial bicuspid aortic valve anatomy required re-operation.

\section{AR}

The cumulative incidence of $\mathrm{AR}>2+$ was $1.4 \% \pm 1.4 \%$ at 5 and 8 years, respectively (Figure 3). All but one patient had no or only trivial AR at the time of discharge. One patient left the hospital with AR graded 2/4. At last follow-up, the AR had decreased and was now trivial, 20 years postoperatively. In addition to the two patients re-operated, another two developed severe AR. Both patients were clinically stable at the time of writing and had relevant regurgitation prior to the Ross procedure and showed normal sinus diameters (30 and $32 \mathrm{~mm}$ ).

\section{Autograft root dilatation}

Pre-operatively, median diameters of annulus, sinus, and STJ were 24 [14-32], 30 [20-49], and 27 [16-42] mm, respectively (Table 1$)$. Twenty-three patients had annular enlargement (>26 mm), of which 16 (Homburg $\mathrm{n}=9$, 


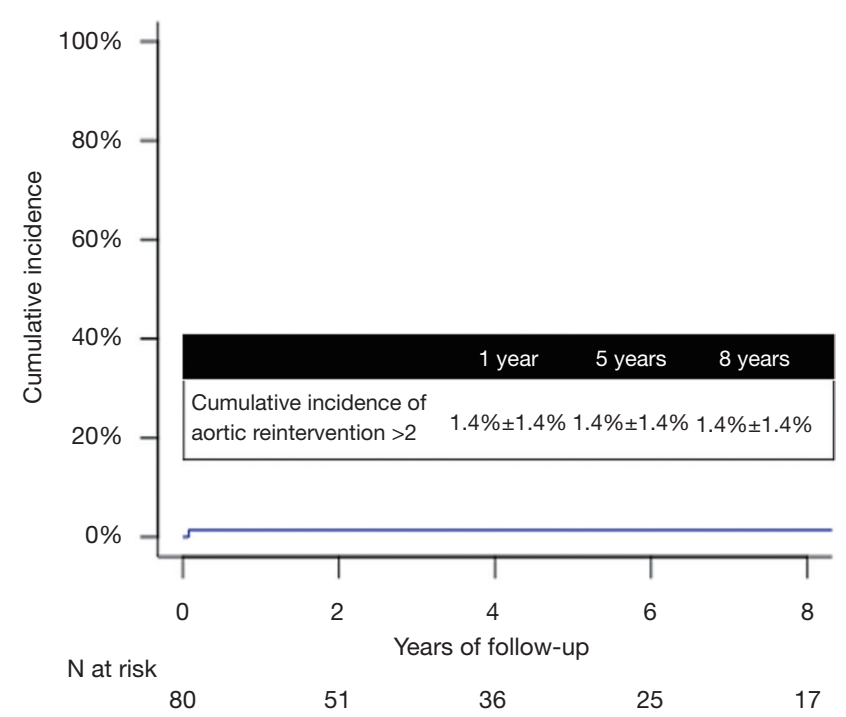

Figure 3 Cumulative incidence of $\mathrm{AR}>2$. AR, aortic regurgitation.

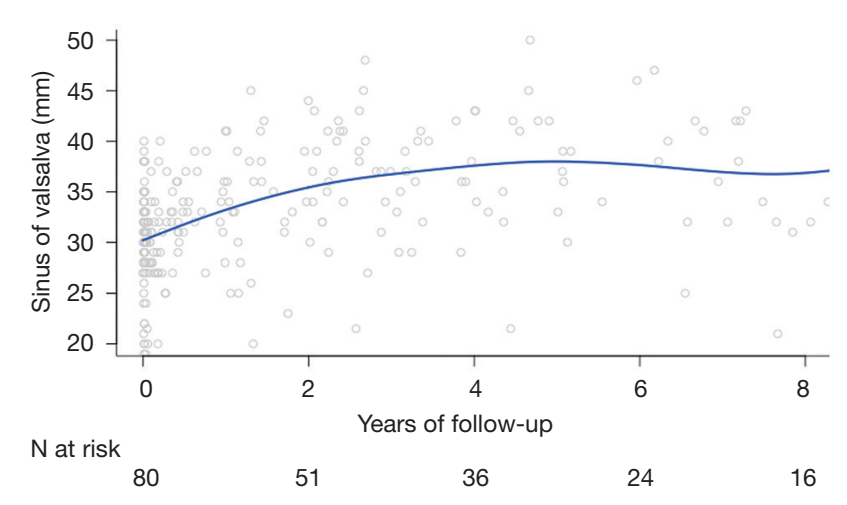

Figure 4 Changes in aortic root (Sinus) diameter in patients undergoing a Ross procedure after an initial valve repair.

Montreal $n=7$ ) underwent an annuloplasty. Among patients with annular enlargement, five showed progressive dilatation during follow-up. Three had an annuloplasty as part of the Ross operation (pericardium n=2, PTFE suture $n=1$ ).

Overall, sinus diameter increased from a mean of $31 \pm 4 \mathrm{~mm}$ (discharge) to mean $37 \pm 8 \mathrm{~mm}$ at 8 years postoperatively $(\mathrm{P}<0.05)$ (Figure 4).

Out of 80 patients, seven developed root dilatation ( $>45 \mathrm{~mm}$ ) over time, a median of $6.2(4.7-10)$ years postoperatively. Progressive dilatation led to re-operation in two cases, while five patients were stable without relevant AR. Cumulatively, in these seven patients, sinus diameters increased from a mean of $33 \pm 3 \mathrm{~mm}$ at discharge to $49 \pm 4 \mathrm{~mm}$ at last follow-up.
Differences were also detected according to original valve morphology. In a cumulative incidence analysis, using death and re-intervention as competing events, patients with a tricuspid valve showed $9.8 \%$ cumulative incidence of sinus dilatation at 5 years. For bicuspid and unicuspid valves, cumulative incidence of sinus dilatation at 5 years was $5.9 \%$ and $37.5 \%$, respectively. There were no events in patients with a quadricuspid or prior prosthesis.

\section{Discussion}

While the Ross procedure remains a relatively complex operation, it is the only replacement operation of the diseased aortic valve with a living substitute. Thus, it allows for adaptive remodeling and normal hemodynamics of the neoaortic valve $(7,8)$. The procedure achieves excellent results in experienced high-volume centers, with long-term survival and quality of life (QoL) equivalent to that of the age- and gender-matched general population (6-8,11-17). Nevertheless, surgical complexity raises concerns about its peri-operative risk and reproducibility, especially when performed as a re-operation (18). As such, the contemporary risk of a Ross procedure as a redo AVR remains poorly defined $(19,20)$.

Aortic valve repair has become a more frequently used alternative to conventional AVR over the past 20 years (21-24). Hemodynamics, QoL and survival are favorable (25). However, recurrent regurgitation and annular dilatation remain of concern $(26,27)$. While the incidence of valve-related complications is low, repair failure remains the most frequent complication (4). At the time of failure, surgeons may prefer the implantation of conventional prostheses as the less complex procedure, thus eliminating the advantages of an autologous valve. As a result, patients are exposed to the long-term complications of conventional valve prostheses (i.e., hemorrhagic complications and excess mortality rates) $(5,28)$.

In attempting to combine the positive effects of a living valve in the aortic position using both aortic valve repair and the Ross procedure, we propose a strategy of initial valve repair followed by an autograft valve replacement in case of failure. Current evidence provides little information on this topic. The results of this study highlight that in selected patients and experienced hands, this strategy is associated with very low peri-operative morbidity and mortality. Indeed, results from these two high volume centers demonstrated no mortalities and a low incidence of 
peri-operative morbidity, as well as low incidence of new pacemaker implantation. Altogether, these results compare favorably with other series of redo-AVR (20).

In addition, as with other studies of primary autograft replacement (13-17), our cohort shows a survival rate equivalent to that of an age- and gender-matched general population. It demonstrates that performing a Ross procedure as a secondary operation after failed aortic valve repair is associated with the same long-term benefits. Endocarditis remains a continuous risk for patients after conventional AVR (29) but is rare after the Ross procedure (7). In our cohort, the risk of re-operation due to endocarditis was $0.28 \%$ per patient-year, which compares to that of a primary Ross procedure $(14,15)$.

Long-term valve durability remains a concern after the Ross procedure, especially in patients with preoperative AR and aortic annular dilatation (30). Autograft regurgitation may occur over time due to cusp deformation or root dilatation (26). The incidence of re-intervention is non-negligible in our cohort. However, of the five reinterventions, three were due to possible infection or peri-aortic cavity formation. The latter is thought to be due to incomplete insertion of the infundibular muscle inside the left ventricular outflow tract during autograft implantation. Of note however, valve-sparing procedures could be performed in all patients with autograft failure, thus preserving the proposed benefit of a living valve in the aortic position.

Significant autograft valve dysfunction and AR $>2$ affected a minority of patients in our study. Several series suggest that a dilated aortic annulus and predominant AR are considered risk factors for late failure (30). While the bicuspid valve phenotype was not associated with reintervention or autograft valve dysfunction, there was however, a higher cumulative incidence of re-intervention for patients with a unicuspid valve morphology. This may be related to the fact that annular dilatation may be more frequent in conjunction with unicuspid morphology than previously thought $(31,32)$.

The main finding from this study is that the full-root Ross technique with a tailored stabilization approach after previous aortic valve repair is associated with excellent survival and durability (33). In our study, mid-term survival is $98 \%$ and is equivalent to that of the age- and gendermatched general population. We therefore consider the Ross procedure a very suitable and safe substitute for the younger patient population, even after previous aortic valve repair. This is relevant in view of limited data on the most suitable valve substitute after failed aortic valve repair. Most published studies have focused on mechanical and tissue prostheses in a redo setting. Our study thus provides a different perspective on the choice of best valve substitute, especially for young patients.

\section{Limitations}

The main limitation of this study is its observational design. Although data of consecutive procedures were obtained prospectively, the analysis was done retrospectively, and treatment allocation was not randomized. Despite being a multi-center study, the sample size was relatively small, with low rate of events, and highly experienced surgeons in high-volume centers performing all procedures. Thus, the reproducibility of our findings may be limited. Despite these limitations, this analysis represents the first available study examining mid-term results of the Ross procedure after aortic valve repair in adults. Further follow-up is ongoing to determine longer term results.

\section{Conclusions}

The Ross procedure after a failed valve repair can be performed with low morbidity and low incidence of reintervention. Mid-term survival is excellent, comparable to that of the age- and gender-matched population. The strategy of initial valve repair, followed by a Ross procedure, maintains the advantages that an autologous valve substitute has to offer. Both procedures bear a low risk of endocarditis, with neither requiring anticoagulation, and hemodynamics at rest and during exercise are excellent. Altogether, these findings suggest that a staged approach centered on the concept of a living valve, consisting of valve repair followed by a Ross procedure in case of failure, represents an excellent option that is associated with favorable perioperative and mid-term results in non-elderly patients with aortic valve disease.

\section{Acknowledgments}

Funding: None.

\section{Footnote}

Conflicts of Interest: The authors have no conflicts of interest to declare. 
Open Access Statement: This is an Open Access article distributed in accordance with the Creative Commons Attribution-NonCommercial-NoDerivs 4.0 International License (CC BY-NC-ND 4.0), which permits the noncommercial replication and distribution of the article with the strict proviso that no changes or edits are made and the original work is properly cited (including links to both the formal publication through the relevant DOI and the license). See: https://creativecommons.org/licenses/by-nc-nd/4.0/.

\section{References}

1. Sievers HH, Stierle U, Charitos EI, et al. Fourteen years' experience with 501 subcoronary Ross procedures: surgical details and results. J Thorac Cardiovasc Surg 2010;140:816-22, 822.e1-5.

2. Aicher D, Kunihara T, Abou Issa O, et al. Valve configuration determines long-term results after repair of the bicuspid aortic valve. Circulation 2011;123:178-85.

3. Svensson LG, Al Kindi AH, Vivacqua A, et al. Long-term durability of bicuspid aortic valve repair. Ann Thorac Surg 2014;97:1539-47; discussion 1548.

4. Aicher D, Fries R, Rodionycheva S, et al. Aortic valve repair leads to a low incidence of valve-related complications. Eur J Cardiothorac Surg 2010;37:127-32.

5. Goldstone AB, Chiu P, Baiocchi M, et al. Mechanical or biologic prostheses for aortic-valve and mitral-valve replacement. N Engl J Med 2017;377:1847-57.

6. Mazine A, El-Hamamsy I, Verma S, et al. Ross procedure in adults for cardiologists and cardiac surgeons. J Am Coll Cardiol 2018;72:2761-77.

7. El-Hamamsy I, Eryigit Z, Stevens LM, et al. Longterm outcomes after autograft versus homograft aortic root replacement in adults with aortic valve disease: a randomised controlled trial. Lancet 2010;376:524-31.

8. Mokhles MM, Rizopoulos D, Andrinopoulou ER, et al. Autograft and pulmonary allograft performance in the second post-operative decade after the Ross procedure: insights from the Rotterdam Prospective Cohort Study. Eur Heart J 2012;33:2213-24.

9. Mazine A, Ghoneim A, El-Hamamsy I. The Ross procedure: how i teach it. Ann Thorac Surg 2018;105:1294-8.

10. Matsushima S, Abeln KB, Karliova I, et al. Suture annuloplasty and simplified root wrapping in the full root Ross operation. Ann Thorac Surg 2019;107:e361-3.

11. Brown JW, Ruzmetov M, Shahriari A, et al. Midterm results of Ross aortic valve replacement: a single-institution experience. Ann Thorac Surg 2009;88:601-7; discussion 607-8.

12. Aicher D, Holz A, Feldner S, et al. Quality of life after aortic valve surgery: Replacement versus reconstruction. J Thorac Cardiovasc Surg 2011;142:e19-24.

13. David TE, Ouzounian M, David CM, et al. Late results of the Ross procedure. J Thorac Cardiovasc Surg 2019;157:201-8.

14. Sievers HH, Stierle U, Charitos EI, et al. A multicentre evaluation of the autograft procedure for young patients undergoing aortic valve replacement: update on the German Ross Registry†. Eur J Cardiothorac Surg 2016;49:212-8.

15. Mastrobuoni S, de Kerchove L, Solari S, et al. The Ross procedure in young adults: over 20 years of experience in our Institution. Eur J Cardiothorac Surg 2016;49:507-12; discussion 512-3.

16. da Costa FD, Takkenberg JJ, Fornazari D, et al. Longterm results of the Ross operation: an 18-year single institutional experience. Eur J Cardiothorac Surg 2014;46:415-22; discussion 422.

17. Skillington PD, Mokhles MM, Takkenberg JJM, et al. The Ross procedure using autologous support of the pulmonary autograft: Techniques and late results. J Thorac Cardiovasc Surg 2015;149:S46-52.

18. Potter DD, Sundt TM, Zehr KJ, et al. Operative risk of reoperative aortic valve replacement. J Thorac Cardiovasc Surg 2005;129:94-103.

19. Luciani GB, Casali G, Favaro A, et al. Fate of the aortic root late after Ross operation. Circulation 2003;108 Suppl 1:II61-7.

20. Leontyev S, Borger MA, Davierwala P, et al. Redo aortic valve surgery: early and late outcomes. Ann Thorac Surg 2011;91:1120-6.

21. Graeter TP, Kindermann M, Fries R, et al. Comparison of aortic valve gradient during exercise after aortic valve reconstruction. Chest 2000;118:1271-7.

22. Collins JD, Semaan E, Barker A, et al. Comparison of hemodynamics after aortic root replacement using valvesparing or bioprosthetic valved conduit. Ann Thorac Surg 2015;100:1556-62.

23. Ashikhmina E, Sundt TM 3rd, Dearani JA, et al. Repair of the bicuspid aortic valve: a viable alternative to replacement with a bioprosthesis. J Thorac Cardiovasc Surg 2010;139:1395-401.

24. de Meester C, Pasquet A, Gerber BL, et al. Valve repair improves the outcome of surgery for chronic severe aortic regurgitation: a propensity score analysis. J Thorac 
Cardiovasc Surg 2014;148:1913-20.

25. Zacek P, Holubec T, Vobornik M, et al. Quality of life after aortic valve repair is similar to Ross patients and superior to mechanical valve replacement: a cross-sectional study. BMC Cardiovasc Disord 2016;16:63.

26. de Kerchove L, Mastrobuoni S, Boodhwani M, et al. The role of annular dimension and annuloplasty in tricuspid aortic valve repair. Eur J Cardiothorac Surg 2016;49:42837; discussion 437-8.

27. de Kerchove L, Jashari R, Boodhwani M, et al. Surgical anatomy of the aortic root: implication for valve-sparing reimplantation and aortic valve annuloplasty. J Thorac Cardiovasc Surg 2015;149:425-33.

28. van Geldorp MW, Eric Jamieson WR, Kappetein AP, et al. Patient outcome after aortic valve replacement with a mechanical or biological prosthesis: weighing lifetime anticoagulant-related event risk against reoperation risk. J Thorac Cardiovasc Surg 2009;137:881-6, 886e1-5.

29. Poh CL, Buratto E, Larobina M, et al. The Ross procedure in adults presenting with bicuspid aortic valve and pure

Cite this article as: Abeln $\mathrm{KB}$, Chauvette V, Poirier N, Matsushima S, El-Hamamsy I, Schäfers HJ. Ross operation after failure of aortic valve repair. Ann Cardiothorac Surg 2021;10(4):476-484. doi: 10.21037/acs-2020-rp-19 aortic regurgitation: $85 \%$ freedom from reoperation at 20 years. Eur J Cardiothorac Surg 2018;54:420-6.

30. Takkenberg JJ, van Herwerden LA, Galema TW, et al. Serial echocardiographic assessment of neo-aortic regurgitation and root dimensions after the modified Ross procedure. J Heart Valve Dis 2006;15:100-6; discussion 106-7.

31. Igarashi T, Matsushima S, Shimizu A, et al. Bicuspidization and annuloplasty provide a functioning configuration to the unicuspid aortic valve. Ann Thorac Surg 2020;110:111-9.

32. Noly PE, Basmadjian L, Bouhout I, et al. New insights into unicuspid aortic valve disease in adults: not just a subtype of bicuspid aortic valves. Can J Cardiol 2016;32:110-6.

33. Bouhout I, Ghoneim A, Tousch M, et al. Impact of a tailored surgical approach on autograft root dimensions in patients undergoing the Ross procedure for aortic regurgitation†. Eur J Cardiothorac Surg 2019;56:959-67. 